\title{
Formation of Cultural Competitive Force When Doing Business in China
}

\author{
Maohua Sun \\ School of Mathematics and Computer Science, Nanjing Normal University \\ Nanjing 210097, China \\ Tel: 86-25-8528-2055Ｅ-mail: dongxiaobo@163.com
}

\begin{abstract}
With the globalization of world business, China has become an appealing market for foreign investors. The problem of cross-cultural management arises as the cooperation between China and its culturally different Western partners continues to increase at an unprecedented rate. This paper presents an understanding on the general cultural differences between the west and China by applying the cultural dimensions of Hofstede and Bond. The author points out that the all-round impact of cultural difference over transnational operation of enterprises affects not only the cooperative strategy, but also the operation and management. It is only through cross-culture communication and management that enterprises can establish good reputation and attain success in its operation. Culture is one of the decisive factors for the success of operation. To realize cross-culture effective management, we must consider solving cultural conflict as the key. In the process of the management, we must pay more attention to the influences of cultural difference on the market choice, product service, entrance mode and system cost, and accordingly formulate a correct strategy, ignore and reduce the cultural difference, or adapt and make use of it. As economic globalization is driving cultural globalization, the culture in the multinational corporation will fuse gradually from differences.
\end{abstract}

Keywords: Transnational operation, Cultural difference, Cultural competitive force

\section{Cultural differences in transnational operation of enterprises and its influence}

\subsection{Cultural differences exist objectively in transnational operation of enterprises}

What is culture? Among researchers who have given a variety of definitions of culture, Hofstede is one of the first to adopt a pragmatic problem-solving approach in the field and relates culture to management. As is pointed out by G.Hofstede that culture is a kind of "collective programming of the mind, which distinguishes the members of one category of people from another" (Hofstede, 1980). With the globalization of world business, China has become an appealing market for foreign investors. The problem of cross-cultural management arises as the cooperation between China and its culturally different Western partners continues to increase at an unprecedented rate. Hofstede explained that culturally-based values systems comprised four dimensions: power distance, individualism/ collectivism, masculinity/femininity, and uncertainty avoidance. Further research by Michael Bond (Bond and Hofstede, 1989, pp. 200) identified a fifth "Eastern" dimension called long-term/short-term. By applying Hofstede's and Bond's cultural dimensions, a cultural comparison between America and China is made. (Pan Fan, K. \& Zhang Zigang, K. , 2004)

Table 1. Cultural Dimension Scores of United States and China

Legend for Chart:

B - Cultural Dimension Scores Power Distance

C - Individualism

D - Masculinity

E - Uncertainty Avoidance

F - Long-term Orientation

\begin{tabular}{lccccc}
\multicolumn{1}{c}{ A } & B & C & D & E & F \\
United States & 40 & 91 & 62 & 46 & 29 \\
China & 80 & 20 & 50 & 60 & 118
\end{tabular}


Table 2. Cultural Differences Between America and China

Legend for Chart:

\section{A - Cultural Dimensions \\ B - USA \\ C - China}

A

B

C

Individualism/Collectivism Strong individualism

Strong Collectivism

Power Distance

Medium

Centralised, tendency

toward democracy

Uncertainty Avoidance Risk-taking

Risk-avoiding

Masculinity/Femininity Medium Masculinity

Medium Femininity

Long/short-term Orientation

\section{Short-term Orientation}

Long-term Orientation

In general, China stresses the social role of the group, whereas Western people emphasize individuality. Collectivism is believed to generate more submissive behavior among Chinese in group interaction processes. Specifically, the collectivist concern of Chinese to avoid interpersonal disharmony becomes salient, and this concern can consequently encourage an Chinese group member to avoid open disagreements with other group members and shift toward the majority position more often than Westerners do. Compared with their Western counterparts, Chinese are more situation-centered and are more externally oriented. Chinese people believes in "yuan", which derives from Buddhism and is often used by Chinese as an explanation for personal outcome by alluding to fate. Westerns admire the self-made person----the one who, with neither money nor family influence, fights his or her way to the top. Chinese culture stresses the importance of maintaining harmonious interpersonal relationships and acting in a manner appropriate to one's position in a hierarchical social situation. Therefore in group interaction processes, they are inclined to be more restrained, cautious, patient, and self-contained, and less impulsive, excitable, spontaneous, and natural than Westerns

\subsection{Major influences caused by cultural differences}

It has been widely accepted that cultural differences greatly affect human thinking and behavior and thus business organizations in which people interact on the basis of shared values. The disadvantageous influences will be discussed from the aspects of strategy Cooperative management and operational management.

\subsubsection{Impact of cultural differences on cooperative strategies}

It is generally believed that entrepreneurs' attitudes toward cooperation are likely to be influenced by the underlying values of their society (Weaver, K Mark. 2000, pp. 591). China is strongly for collectivism and medium feminism. The Chinese depend more on groups or institutions to determine what they should do and emphasize loyalty to the group. They are more likely to cooperate with others to avoid risks and reduce responsibilities. Their value systems appreciate duty to the group and harmony among its members while pursuing personal goals is viewed rather negatively in Chinese society. While as discussed above, western people are strongly for individualism and medium masculine. They depend on their own view to determine what they should do. They tend to work alone and are reluctant to cooperate because their individualism and masculine culture view cooperation in general as a sign of weakness and place a high value on independence and control. On the other hand, The Chinese and westerns tend to resolve conflicts in different ways. Since the Chinese believe in a strong collectivism and medium feminine society in which harmony and personal relationship are emphasized, they will try to make full use of indirect ways to avoid direct and open conflict. When they face conflict, they prefer to use authority to suppress it, or settle things in private. They prefer to resolve conflict through negotiation and compromise. Individualistic and medium masculine western managers are used to confronting problems directly and bringing things out in the open. In addition, Western managers are reluctant to invest the time and effort required to enlist the help of other people, when they have conflicts or problems with another party. In contrast, 
the strong collective orientation and uncertainty avoidance values in China encourage Chinese managers to use indirect forms of influence that involve the assistance of a third party (Bond $M$ and G Hofstede, 1989, pp 195).

To deal with a difficult or controversial request, indirect forms of influence are preferred by Chinese managers to avoid losing face and damaging guanxi. When their Western partners propose to use direct and open ways to deal with the conflict, they may feel embarrassed. On the other hand, Western partners may get totally confused by the roundabout way the Chinese use to solve seemingly simple problems. The different ways that Chinese and Western managers resolve conflicts seem to find support from Weaver's finding that feminine societies prefer to resolve conflict through negotiation and compromise. (Weaver, K Mark, 2000, pp. 609)

\subsubsection{Impact of cultural differences on transnational operating management}

Cultural differences certainly lead to market opportunity loss and low efficiency. On inner management the differences of value concept, life objective and behavior norm results in increased administrative expenses, the difficulties in integration and practice of enterprise target, in the long run, will enhance operating management cost of the enterprise. On outside operation differences of languages, habits and values make operating environments more complex and increase the difficulties of market operation. The research based on dozens of Sino-American enterprises by John koter, a professor from school of business in Harvard University, indicates that enterprise's cultural differences substantially affected enterprise's operating accomplishments of long standing. Operating accomplishments of the corporations, which place high emphasis on all key managing elements (consumers, shareholders, employees) and leading arts of the personnel at all levels are far superior to those of the ones without such kind of characteristics of enterprise cultures. Gross earnings of the former averagely increases $682 \%$, those of the latter only amounts to $166 \%$; enterprise employee of the former increases $282 \%$, those of the latter is $36 \%$; the company stock price of the former increases to $901 \%$, those of the latter is $74 \%$; the net income increase of the former is $756 \%$, and those of the latter is $1 \%$. (Shi, Tianlin, Ma, Yangxiang \& Fan, Jin, 2004, p. 90)

It goes without saying that if the enterprise doesn't proceed to communicate effectively aimed at the cultural difference, cultural clash from either different types or different elements of culture will occur. This kind of clash includes the conflict with cultural concepts of the host country in transnational operation of enterprises as well as inside conflict among clerks coming from different counties and different areas. The core task of cross-cultural management is to solve cultural clash. It is only through cross-culture communication and management that enterprises can establish good reputation and attain success in its operation. Culture is one of the decisive factors for the success of operation.

\section{Cultural blending and formation of cultural competitive force}

\subsection{Cultural blending is a trend of globalization}

Cultural clash derives from cultural difference. Different cultural categories determine different degree and different type of cultural clash. As Edward Hall, U.S. anthropologist, put it that culture can be divided into three categories: formal norm, informal norm and technique norm. The formal norm is the person's basic value and judging standard on the right and the wrong, which can resist the exterior power that tried to change it. Therefore, the friction caused by formal norm usually cannot be changed easily. The informal norm is people's living habits and customs etc. Its caused cultural friction can be overcome through cultural interaction of long standing. The technique norm can be obtained by the study of the technique knowledge and changed very easily. Therefore, in the process of transnational operation the enterprise should, acting on the law and aiming at different "culture conflicts" caused by "cultural differences", blend the concept of value, operating scope, moral behavior standard and organizational structures and proceeds to practice gradually cross-cultural management. In the process of the management, the enterprise must pay more attention to the influences of cultural difference on the market choice, product service; entrance mode and system cost, and accordingly formulate a correct strategy, ignore and reduce the cultural difference, or adapt and make use of it. As economic globalization is driving cultural globalization, the culture in the multinational corporation will fuse gradually from differences. To form a strong cultural competitive force in world market, the enterprise should absorb various cultural nourishments, emphasize on the use and embody going with the times on the bases of inheriting good traditions and managing styles.

\subsection{What is cultural competitive force?}

What is cultural competitive force? Generally speaking, It is a kind of cohesive force,, leading force, inspiriting force and pushing force caused by all kinds of cultural factors pushing economic advance and human all-round development. It mainly embodies in three aspects: firstly cultural creative ability; compared with other creations, cultural creation has special meanings. In a sense, creation is the life of culture. Whether cultural product is competitive or not mainly depends on cultural creation. Secondly cultural transferring ability, which means enterprise's culture can be easily adapted to popular culture and simultaneously accepted by main culture. Thirdly high-quality talents, In transnational operation of enterprises high-quality bicultural or multicultural talents is core of cultural competitive force. 


\subsection{Modes of the formation of cultural competitive force}

\subsubsection{Mode of localization}

Because of governmental inflexible rule in host country, especially because the native employee acquaints with the native macro and micro environment, choosing and training the native personnel to manage and operate the abroad subsidiaries not only benefit the multinational company to lower the high cost of sending personnel abroad but also can blend with native social culture, reduce crisis motion the region society facing outward capital, benefit the transnational corporation to expand the market in the region and stand firmly the heel. Meanwhile, the mode benefit employment opportunities in host country, improving managing level, and the both parties' interests .Therefore localization strategy become the basic guiding thought of many multinational companies to practice cross-cultural management.

\subsubsection{Mode of culture transplantation}

The main characteristic of culture transplantation is that key positions of the enterprise held by the people from mother country. The precondition using this mode is that the multinational company have mighty economic power and have enormous influence in the world, in addition its corporate culture has been recognized all over the world and accepted by other nationalities. U.S. McDonald's is a good typical example.

\subsubsection{Mode of culture grafting}

The mode requires using mother country culture as the corpus culture of the subsidiary,meanwhile, marrying the host country culture to the mother country culture. Its advantage is successfully to consider global unified strategy and different backgrounds of host country culture, while its disadvantage is that whether succeed or fail require many specific demands.

\subsubsection{Multi-cross mode}

As international business activities increasingly globalize, the products create quickly, different nationalities communicate multifariously, the individuals of multinational group company appeared multi-cross cultural trend. To avoid cultural conflicts caused by cultural differences in inner part of parent company, in inner part of subsidiary and between parent company and subsidiary, the following staff should be chosen carefully: (1) foreigners with the native nationalities of mother country ;(2) native people with local nationalities;(3) local foreigners studying and working in mother country;(4) native people studying and working in local country; etc.

\subsubsection{Mode of asking for help}

If the multinational company can't adapt to completely the environment of the host country in a short time, usually ask for help from comparatively neutral culture of the third party which has reached agreement with the mother country's culture for management in order to avoid direct conflict between mother country's culture and host country's culture.

\section{Conclusion}

To sum up, in the process of transnational operations of enterprise the managing staff must adapt to inevitable trend of culture developing from the single to the multiple and come to know all kinds of disadvantageous influences caused by cultural differences. They should continuously study and practice to master a variety of arts and techniques of cross-cultural management and communication. To improve its cultural competitive force throughout world market, the enterprise should choose appropriate modes of depending on its own situations and gradually increase its own cultural transferring ability. The formation of cultural competitive force needs a long way to go. In the long run only the enterprise having cultural competitive force can establish good reputation in international market and gain operating success.

\section{References}

Bond M and G Hofstede. (1989). The cash value of Confucian values. Human System Management, 8, pp 195

Bond, M \& G, Hofstede. (1989). The cash value of Confucian values, Human System Management, 8, pp. 200.

Hofstede G. (1980). Culture's consequences: International differences in work-related values. Beverly Hills, CA: Sage.

Pan Fan, K. \& Zhang Zigang, K. (2004). Cross-cultural Challenges when Doing Business in China: Singapore Management Review, 01295977, 2004 1st Half, Vol. 26, Issue 1

Shi, Tianlin, Ma, Yangxiang \& Fan, Jin. (2004). Cross-cultural management in transnational operation of Enterprises. Journal of Shanxi Finance And Economics University, (2), p. 90 (Chinese)

Weaver, K Mark. (2000). Attitudes toward Cooperative Strategies: A Cross-Cultural Analysis of Entrepreneurs. Journal of International Business Studies, 31, Fourth Quarter 2000: pp 591

Weaver, K Mark. (2000). Attitudes toward Cooperative Strategies: A Cross-Cultural Analysis of Entrepreneurs. Journal of International Business Studies, 31, Fourth Quarter 2000: pp. 609. 